\title{
Diversidade Cultural e Alfabetização de Pessoas Jovens e Adultas na Guiné-Bissau
}

\author{
Diversidad Cultural y Alfabetización de Personas Jóvenes y Adultos en la \\ Guinea-Bissau
}

\section{Cultural Diversity and Literacy of Young and Adult Persons in Guinea- Bissau}

\author{
Simone Valdete Dos Santos ${ }^{1}$ \\ Arrais Fidelis da Silva Gomes ${ }^{2}$
}

\begin{abstract}
Resumo
A diversidade cultural, cosmologias próprias vinculadas a diferentes idiomas e religiosidades compõe uma "África Profunda", conforme a obra do filósofo argentino Rodolfo Kusch, sendo esta base teóricometodológica para o levantamento bibliográfico e documental sobre a Alfabetização de Pessoas Jovens e Adultas na Guiné Bissau, sendo localizadas três dissertações de mestrado e uma tese de doutorado. Os estudos revelam a precariedade do sistema educacional guineense, herança das políticas coloniais europeias e a emergência da diversidade cultural compor os currículos das classes de Alfabetização das Pessoas Jovens e Adultas.
\end{abstract}

Palavras-Chave: Alfabetização de Jovens e Adultos; Diversidade Cultural; Guiné-Bissau

\section{Resumen}

La diversidad cultural, cosmologías propias vinculadas a diferentes idiomas y religiosidades compone una "África Profunda", conforme a la obra del filósofo argentino Rodolfo Kusch, siendo esta base teóricometodológica para el levantamiento bibliográfico y documental sobre la Alfabetización de Personas Jóvenes y Adultas en Guinea Bissau, siendo localizadas tres disertaciones de maestría y una tesis de doctorado. Los estudios revelan la precariedad del sistema educativo guineano, herencia de las políticas coloniales europeas y la emergencia de la diversidad cultural componiendo los currículos de las clases de Alfabetización de las Personas Jóvenes y Adultas.

Palabras clave: Alfabetización de Jóvenes y Adultos; Diversidad Cultural; Guinea-Bissau

\begin{abstract}
Cultural diversity, its own cosmologies linked to different languages and religiosities, make up a "Deep Africa", according to the work of the Argentine philosopher Rodolfo Kusch, and this theoretical-methodological basis for the bibliographical and documentary survey on Literacy of Young and Adult People in Guinea- Bissau, where three master's dissertations and a doctoral thesis were located. The studies reveal the precariousness of the Guinean educational system, inheritance of European colonial policies and the emergence of cultural diversity compose the curricula of the Literacy classes of the Young and Adult.
\end{abstract}

\footnotetext{
1 Professora Titular na Universidade Federal do Rio Grande do Sul, possui Licenciatura em História pela Universidade do Vale do Rio dos Sinos (1994), mestre em Educação pela Universidade Federal do Rio Grande do Sul (1998), Doutorado em Educação pela Universidade Federal do Rio Grande do Sul (2003) e doutorado em Educação na modalidade sanduíche pela Universidade Federal Fluminense (2000). Vinculada ao Programa de PósGraduação em Educação da Universidade Federal do Rio Grande do Sul.

${ }^{2}$ Possui graduação em Ciências Sociais pela Universidade Federal do Rio Grande do Sul (2015) e graduação em Ciências Sociais pela Universidade Federal do Rio Grande do Sul (2012). Mestre em Educação na Linha de Pesquisa: Políticas e Gestão de Processos Educacionais pela Universidade Federal do Rio Grande do Sul (2018).
} 
Key words: Youth and Adult Literacy; Cultural Diversity; Guinea-Bissau

\section{Introdução}

A escrita e a leitura foram e são tecnologias essenciais para a constituição da Modernidade e sua consequente organização do Estado Moderno e capitalista. Neste sentido, os grupos humanos alijados desta tecnologia estão à margem, são e estão outsiders no modelo de organização social, econômica e política do capitalismo.

As populações dos países africanos encontram-se, majoritariamente, na condição de analfabetismo absoluto, vinculadas ao status quo da fase atual do capitalismo que privilegia as tecnologias da informação, permanecem na condição de desigualdade como a então forjada no século XV com a expansão dos então Estados Nacionais europeus e organização das políticas colonialistas.

O presente texto expressa o interesse da pesquisa sobre a Alfabetização de Pessoas Jovens e Adultas na Guiné Bissau, considerando que grande número de habitantes da população vive na linha de pobreza, com um índice de analfabetismo muito elevado e nível de escolarização muito baixo, o que atinge principalmente as mulheres. O país enfrenta grande dificuldade decorrente da posição secundária da alfabetização de jovens e adultos na agenda política e da falta de recursos financeiros, materiais e humanos para o setor educacional.

Para desenvolver uma proposta de Educação Libertadora com características africanas, é preciso partir do encontro contraditório, porém daquilo que não pode ser separado entre cultura europeia, indígena e africana. A primeira identificada com o projeto da modernidade burguesa, branca e capitalista, e as outras duas, as dominadas, que carregam até hoje as consequências do processo permanente de subalternidade e de resistência: a colonialidade. Acreditamos que a atitude adequada não seja negar o legado da modernidade, mas reconhecêlo e contextualizá-lo histórica e epistemologicamente. O reconhecimento da lógica monocultora eurocêntrica, a fim de abrir caminhos para outros paradigmas.

Segundo Kusch (1999), estamos comprometidos com a América muito mais do que pensamos estar, uma vez que, encontrar o seu caminho neste mundo é assumir a excentridade da nossa situação cultural e, sobretudo religiosa; não para nos emanciparmos dos laços tradicionais, mas para reivindicar a particularidade destes vínculos. Em nosso entendimento, tal pressuposto também vale para África. 
Quando pensamos em políticas educacionais, de um modo geral, pensamos em alguém ensinando e outro alguém aprendendo. As políticas educacionais precisam ser tratadas como um compartilhamento de experiências de ambas as partes.

Para Paulo Freire, o aluno desenvolve o ato de conhecer e produzir conhecimento encharcado de algumas qualidades: ação, reflexão crítica, curiosidade, questionamento exigente, inquietação, incerteza. Sendo assim, a Educação de natureza integradora, na qual professores e alunos possam criar e recriar o conhecimento e compartilhá-lo mutuamente. Estimula-se o diálogo reflexivo e democrático dentro de um clima de responsabilidade, direcionamento, determinação e disciplina. Nesta concepção, não há dicotomia entre ensino e pesquisa, pois esta última se desenvolve na própria sala de aula (FREIRE, 2003).

Entende-se que a política educacional promovida pelo Estado guineense, precisa considerar as especificidades culturais e religiosas e operar em cooperação com setores da sociedade engajados neste objetivo e que atuam no sistema formal e não formal de ensino.

Tal perspectiva corrobora para a reflexão sobre as políticas adotadas na Alfabetização de Pessoas Jovens e Adultas na Guiné Bissau, principalmente com a influência da gestão escolar no processo de alfabetização desses alunos e na implementação curricular destas experiências.

Para alguns autores a construção das políticas públicas não é um processo abstrato. Ela é, ao contrário, indissociável da ação dos indivíduos ou dos grupos envolvidos, de sua capacidade de produzir discursos coerentes de seus modos de mobilização e de acordo com autores essas análises substantivas não apenas para entender as atuais políticas educacionais, mas também as mudanças que vem ocorrendo globalmente na Educação e essas transformações no campo educacional são também perpassadas pelas modificações que vem ocorrendo no setor público. Ainda essas mudanças que envolvem desde as formas de emprego, sistema de financiamento, administração incluindo as relações sociais devem ser vistas como integrantes de um estado, de um processo de mudança mais amplo e globalizado.

As concepções do filósofo argentino Rodolfo Kusch, as quais valorizam a cultura local, traduzida nas diversidades étnicas, suas línguas, suas religiões, seu modo de ser e estar no mundo são base teórica e metodológica do trabalho. Princípios da obra de Paulo Freire também corroboram para análise documental e bibliográfica sobre as experiências pedagógicas existentes na Alfabetização de Pessoas Jovens e Adultas na Guiné Bissau. 


\section{Localização Geográfica e Política da Guiné-Bissau}

A Guiné-Bissau é um país africano, situado na costa ocidental da África limitada ao Norte pelo Senegal e ao Sul pela Guiné-Conakry (ex-colônia francesa), com superfície total de $36.125 \mathrm{~km}^{2}$, constituído por uma diversidade étnica e cultural ampla.

A população totaliza cerca de 2.000 .000 habitantes, apresentando um analfabetismo de $49,8 \%$, sendo $20 \%$ masculino e $80 \%$ feminino, com os índices mais elevados nas áreas rurais. No Índice de Desenvolvimento Humano (IDH) está posicionado em $167^{\circ}$ lugar, evidenciando, assim, a sua condição de um dos países mais pobres do mundo. O português é falado por apenas $12 \%$ da população e a diversidade linguística confere complexidade à tarefa de alfabetização de jovens e adultos, que, atualmente, é implementada também na língua nacional que é o crioulo. Conforme dados apresentados pelo Ministério da Economia Plano e Integração Regional, através do Instituto Nacional da Estatística (INE) no último censo realizado em 2009 mostrou um crescimento da população guineense que é de 1.520.830 e ao nível do país, a cidade de Bissau com 387.909 pessoas, Região de Oio com 224. 644; Região de Gabú com 215. 530; Região de Bafatá com 210.07; Região de Cacheu com 192.508; Região de Biombo com 97.120; Região de Tombali com 94. 939; Região de Quinara com 63.610 e Região de Bolama Bijagós com 34.563.

Os órgãos ou instituições civis que promovem a alfabetização de jovens e adultos no país são: Organizações Não Governamentais (ONGs), entidades religiosas (igreja católica, evangélicas, mesquitas) e associações de bairros.

A herança cultural da Guiné Bissau é diversificada, composta por aproximadamente vinte ou mais grupos étnicos, sendo que alguns já estão em extinção (Fulupis, Sussus, dentre outros). Tal diversidade ocorre tanto no aspecto linguístico como na música, dança, artesanato e outras manifestações culturais. Contudo, oficialmente, a existência do componente étnico continua sendo negligenciada pelo poder público, o desconhecimento das tradições étnicas e a continuidade dos princípios eurocêntricos de entendimento das culturas fazem com que alguns analistas internacionais identifiquem estes grupos étnicos como um dos entraves ao processo democrático nacional, para a "construção de uma verdadeira nação", ainda em conformidade à mentalidade que resultou em inúmeras guerras e conflitos de dominação dos territórios, das riquezas e dos seres humanos dos então países africanos. As fronteiras foram construídas dentro das políticas colonialistas dos países europeus e usurparam realidades locais existentes. 


\section{Diversidade Cultural e a Variedade Linguística na Guiné-Bissau}

Embora o português seja a língua oficial da Guiné-Bissau e consequentemente a língua oficial do ensino no país, continua até os dias de hoje como a terceira língua falada no país, com cerca de $12 \%$ dos falantes, enquanto a língua crioula conta com cerca de $44 \%$ de falantes, dependendo dos casos. Ou seja, das famílias, a primeira língua pode ser o crioulo, depois a língua étnica a que a família pertence, e por último o português. Essa ordem pode mudar no topo, principalmente nos interiores do país, onde na maioria dos casos a primeira língua é a do grupo étnico a que a família pertence seguida pelo crioulo como a segunda língua da família.

O português, na maior parte das famílias é considerado uma língua estranha; nem se quer é falada no seio dessas famílias, salvo pelas crianças e alguns adultos que frequentam as escolas, mas mesmo nesse caso elas só falam o português nas escolas e em casa é a língua étnica ou o crioulo. Porém, a língua mais falada no país no dia a dia da população, dos estudantes e até dos políticos é o crioulo, ao passo que nas escolas se ensina a língua portuguesa, língua que não se consolidou no país.

A maioria da população que fala o Português está centralizada na cidade Bissau; com isso, a Língua Portuguesa limitou-se basicamente na capital do país, enquanto a maioria da população guineense continua a se comunicar com a Língua Crioula e os restantes se comunicam apenas com as línguas do seu respectivo grupo étnico. Esses fatores evidenciam que a Língua Portuguesa não está consolidada em todo o território nacional, as crianças e adultos sofrem com o ensino oficial da Língua Portuguesa, enfrentando muitas dificuldades na compreensão dos textos a serem estudados:

\footnotetext{
Os alunos não percebem a língua portuguesa. Leem, mas não compreendem o texto, alguns alunos não escrevem o português correto. Como é que um estudante que não escreve e nem fala correto a língua portuguesa pode compreender e interpretar um texto nesta língua? As vezes compreendem melhor quando a explicação é na língua crioula, eu já tive essa experiência. Por vezes (...) é preciso desenhar bem as coisas para fazer alguns alunos compreender em língua portuguesa. (BARRETO, 2014, p. 26).
}

A diversidade cultural e linguística é uma grande riqueza. Não uma deficiência. O processo de alfabetização de jovens e adultos deverá considerar a necessidade de criação de materiais e conteúdos diferenciados tendo em conta as diversidades culturais e linguísticas.

A maioria das sociedades africanas foi estruturada em torno da cultura oral, como sustenta (Faundez, 1989, P. 74), numa cultura essencialmente de expressão oral, a educação precisa levar em consideração os conteúdos, os meios de transmissão da cultura. Não convém, 
pois, privilegiar a expressão cultural escrita em detrimento da expressão oral. É indispensável comparar e permitir o desenvolvimento mútuo das duas expressões. A linguagem tem tudo a ver com o poder.

Como diz Donaldo Macedo (2000), não basta conhecer apenas uma modalidade de língua. Ele salienta que é importante conhecer a língua popular, captando-lhe a espontaneidade, a expressividade e sua enorme criatividade. Não se trata de negar a importância, mas sim de valorizar a forma linguística que cada povo coloca como norma geral, para garantir a valorização da própria língua nacional. Mas, como a linguagem sempre representa um poder, ela pode ter e tem força política. Um dominador, um colonizador, quando chega a um país, a primeira coisa que faz é impor aos nativos a sua língua para poder facilitar o seu entendimento com aquele povo.

Como já referimos, a língua nacional da Guiné Bissau é o Crioulo, sendo o Português a língua oficial e de comunicação com o exterior, existindo, porém, outras línguas faladas pela população local, cuja distribuição segue de perto a divisão do país em grupos étnicos, que é a seguinte: Balantas (27\%), os Fulas (22\%), os Mandingas (12\%), os Manjacos (11\%), os Papeis (10\%) e os outros (18\%).

A maioria dos guineenses pratica religiões tradicionais de origem africana (54\%), o islamismo (38\%) e o cristianismo (8\%). Fula, Mandingas e Biafadas são grupos islamizados, seguido por grupos que praticam, majoritariamente, religiões tradicionais africanas. $\mathrm{O}$ cristianismo está representado apenas por uma minoria que reside em área urbana. Exemplo: 


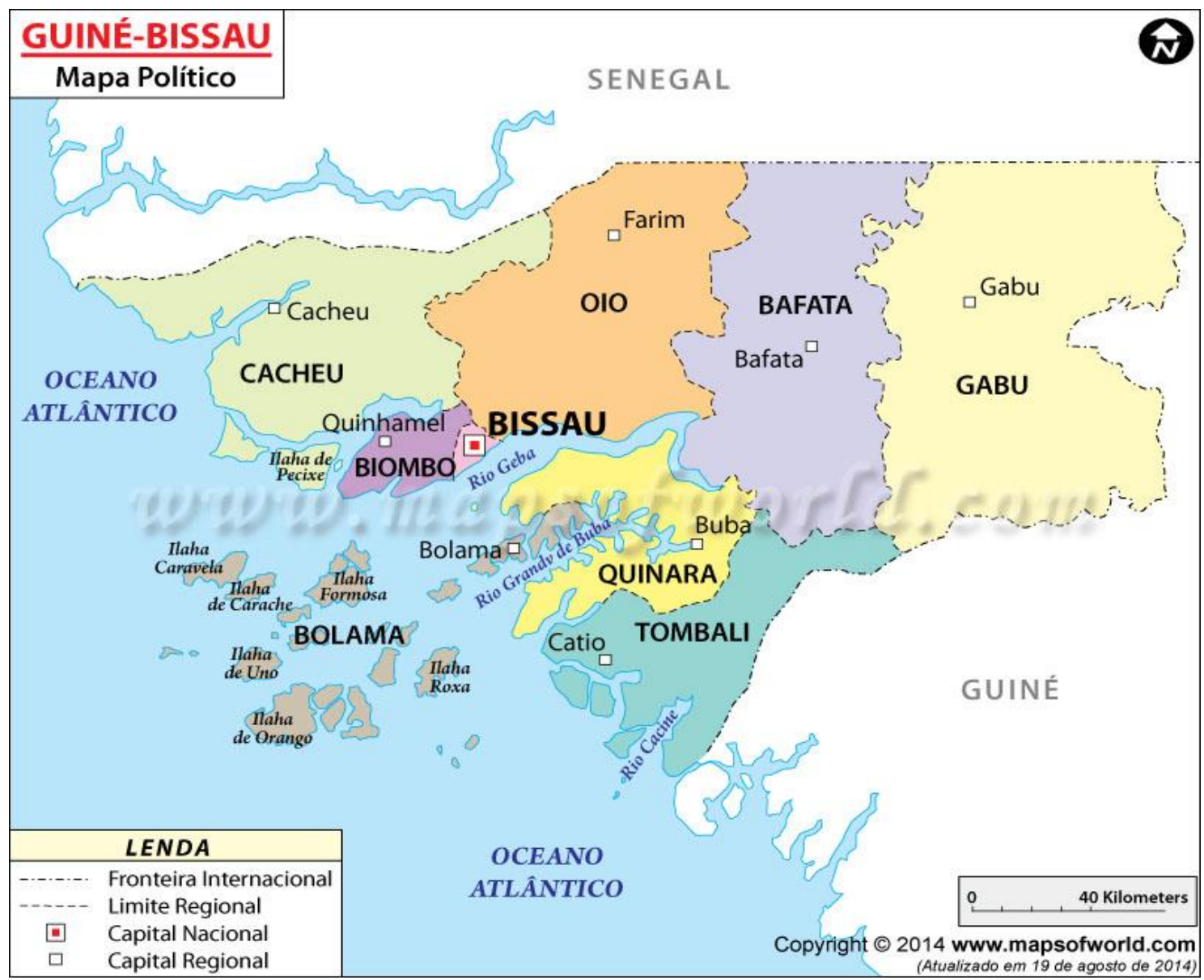

Figura 1 - Mapa Geográfico de Regiões da Guiné-Bissau. ${ }^{3}$ Fonte: http://pt.mapsofworld.com/guinea-bissau/631, 2014.

Os dados sobre Alfabetização de Pessoas Jovens e Adultas, políticas educacionais da Guiné Bissau estão disponíveis especialmente nas páginas da rede mundial de computadores vinculadas à Organização das Nações Unidas para a Educação, a Ciência e a Cultura (UNESCO), junto ao Ministério da Educação há poucos dados e, a maioria da execução de turmas de Alfabetização de Pessoas Jovens e Adultas é promovida por organizações não governamentais e Igrejas, não ocorrendo um comprometimento efetivo do Governo da Guiné Bissau.

A questão da linguagem, no fundo, uma questão de classe, é igualmente outro ponto em que pode emperrar a prática progressista. Um educador progressista que não seja sensível à linguagem popular, que não busque intimidade com o uso de metáforas, das parábolas no meio popular não pode comunicar com os educandos, perde eficiência, é incompetente. (FREIRE, 2001, apud CORTESÃO, 2011, p. 100).

\footnotetext{
${ }^{3}$ Disponível em: http://pt.mapsofworld.com/guinea-bissau/631. Acesso em 22/12/2017.
} 
A língua é um fator importantíssimo para qualquer que seja o processo de aprendizagem, pois é com ela que podemos estabelecer a comunicação e consequentemente o diálogo que faz criar o ambiente da produção do conhecimento, sem o qual este ficaria complicado. Por isso que Freire acredita que a melhor forma de ensinar é por via da língua materna, que é a língua que as pessoas têm mais probabilidade de dominar.

Segundo Cá (2010), o Estado poderia verificar o quadro de dificuldades que o sistema educativo enfrenta de forma a amenizar os obstáculos do sistema, no que diz respeito à questão da língua, para ele, a linguagem não é usada apenas para veicular informação, ou seja, ela vai, além disso. Porém, sua função referencial ou denotativa não é se não uma entre outras, em que se destaca a função de comunicador ao ouvinte. Portanto, devem ser tomadas as medidas aceitáveis a fim de atender pelo menos às exigências básicas.

É evidente a ligação das etnias com os grupos de interesse no processo de consolidação da democracia na Guiné-Bissau, assim como de grupos religiosos entre outros. Essa situação neste trabalho não é abordada de forma negativa ou pejorativa, mas sim como fator importante nestas relações a serem consideradas na construção do entendimento sobre o contexto político da Educação pública no país.

Mas, é indicativo dos conflitos e situação emblemática da importação do modelo de democracia ocidental que, ao se sobrepor as identidades étnicas nos diferentes territórios em que "reis" comandavam sua população nativa, ocasionaram uma desorganização sóciopolítica nestes espaços. A cada governo derrubado, emerge outro comando violento que coloca um interventor na região $\mathrm{A}$ ou $\mathrm{B}$, gerando insatisfação aos povos. De acordo com Sambú (1989):

A influência étnica se instalou no PAIGC ${ }^{4}$, no período pós 14 de Novembro de 1980, têm duas possíveis explicações: a primeira é a disputa entre Mandingas e Biafadas liderada, sobretudo, pelos coronéis Iafai Camará e Ansumane Mané ante Balantas, sob a liderança de Paulo Correia e Viriato Pã, a segunda foi à consequência do referido antagonismo que resultou na fomentação das intrigas palacianas atribuindo poderes às armações da polícia política (civil e militar) que culminou em prisão arbitrária e fuzilamento de militantes e altos responsáveis do partido, majoritariamente da etnia Balanta. (SAMBÚ, 1989, p. 159).

Em relação à explicação da vertente étnica no conflito guineense e, principalmente, à tentativa de identificar ou rotular alguns grupos como "guerreiros por natureza", vale discordar de afirmações que apontam aos Balantas tal característica. A adesão massiva dos Balantas à luta de libertação nacional tem que ser observada, entre vários outros fatores, como

\footnotetext{
${ }^{4}$ Partido Africano para a Independência da Guiné e Cabo-Verde - nota nossa.
} 
uma imposição circunstancial. Ou seja, o teatro da luta decorreu em uma região predominantemente habitada por esse grupo étnico e, na situação de sofrimento a que inevitavelmente estavam expostas, seus habitantes foram obrigados a aderir à luta como meio de se defender dos violentos ataques. Isso é utilizado como justificativa para exercer influência nos espaços de poder político. No mais, o desencadeamento da luta na região sul e norte, principalmente, não foi apenas pela "valentia dos grupos étnicos" que habitam a região, em grande parte Balantas e Mandingas.

Mas, Amílcar Cabral (1956) no seu estudo agrário sobre os solos da Guiné conseguiu observar a mais valia dos fatores geográficos e climáticos que essas regiões podem oferecer ao desenvolvimento no decorrer das lutas pela independência. Referente às estratégias é que se destacam os Balantas, devido às características de seu território, pouco conhecido aos portugueses. Para além, esta etnia previa assim o apoio dos países vizinhos já independentes (Senegal e Guiné-Conakry). Enquanto o segundo ponto se fundamentava na retaguarda da vizinha Guiné-Conakry. Essa tática dos Balantas de acordo com seus territórios previa as dificuldades que as densas florestas, chuvas intensas, rios e pântanos poderiam causar às tropas coloniais que, naturalmente, não estavam habituadas a estas características climáticas.

Nesse sentido, não se deve subestimar a contribuição e o destaque dos Balantas na defesa da independência da Guiné, só que desconsiderar outros fatores nessa leitura pode ocultar a compreensão da realidade em redor, no que se refere à defesa de seus interesses na disputa política do país.

Para estes a forte presença da pertença étnica no comportamento dos cidadãos está a inibir atualmente o sentimento da nação e a abrir possibilidades para o acirramento do conflito de caráter étnico. Não obstante, o PAIGC, por ter surgido em um momento particular da história nacional em que havia uma mobilização à unidade nacional, internamente, é muito difícil perceber na sua estrutura política a predominância de um dos grupos étnicos específicos. Em nenhum momento um grupo conseguiu ter o domínio visível ao ponto de provocar insatisfação entre outros militantes. Grande maioria das manifestações conflituosas acontece na estrutura da Força Armada Revolucionária do Povo (FARP). Por que isso acontecia? Na abordagem de Delfim Silva (2003) “Após o golpe de 1980, os Balantas que sempre constituíram o grupo majoritário na FARP, eram vistos pelo então poder como uma ameaça, entretanto, esse sentimento de que os Balantas constituem perigo dentro da força armada". (p.144).

Esse processo de constituição do perfil da etnia como de ameaça impediu que seus oficiais ocupassem cargos estratégicos de mando na estrutura militar como, por exemplo, o de 
chefia de Estado-Maior ou dos três ramos Marinha, Exército, e Força Aérea. Esse comportamento tácito posteriormente foi reforçado pela existência excessiva de corrupção na administração pública, tráfico de armas e de drogas que contribuíram com a instalação da lógica da violência e dos conflitos.

No limiar dos primeiros anos da era da independência, a política do PAIGC levou-se agressiva, se não francamente repressiva, em relação às igrejas e mais precisamente a católica, a qual vinha assumindo um papel de liderança no contexto dos domínios portugueses. A obra política tangível de Amílcar Cabral é essencialmente de orientação laica, ela não evidencia os traços da rejeição radical do papel das entidades religiosas. Contudo, a prática da liderança do PAIGC uma vez instalada no poder foi subtrair as identidades religiosas do seu papel social. Dois motivos guiaram suas ações: o primeiro era a antecedência negativa atribuída aos cleros católicos e muçulmanos acusados de terem sido apoiadores da política "paternalista do colonizador português"; e o segundo era a vontade do PAIGC de exercer um controle central em todos os espaços da sociedade para criar as condições para execução do seu projeto político.

A pretensa emergência do "homem novo", cidadão exemplar da nova sociedade, perspectiva do partido único, implicava uma ação abrangente, percebia o papel social das instituições religiosas como concorrente ao poder do Estado.

O PAIGC, embora não tivesse enveredado por ações diretas contra a religião em si, desenvolveu uma política de redução e confinação do papel social das igrejas, principalmente, nas obras sociais das instituições católicas que detinham uma reconhecida predominância na matéria. Por outro lado, durante quinze anos, por sua hegemonia no controle do estado com a assunção do partido único e das organizações em massa, as igrejas só voltaram a ter uma maior visibilidade e uma nítida liberdade de ação na sequência das liberalizações ocorridas no final da década de 80 e início dos anos 90.

A liberalização econômica e a consequente redução do papel intervencionista do Estado permitiriam um reacender do papel social da Igreja Católica. Uma nova presença é tanto mais apreciada quanto o controle total anteriormente exercido pelo estado se revelará infrutuoso e mesmo sinônimo de regressão. Particularmente, nas escolas e internatos nacionalizados, que caíram em ruínas, depois de escassos anos de gestão estatal. A forte presença da Igreja Católica no domínio sanitário, o seu envolvimento cada vez maior nas organizações da sociedade civil, de apoio à juventude, de alívio da pobreza, entre outros, são fatores que contribuem ao seu retorno. Ainda a influência social da Igreja Católica é favorecida pelo novo contexto de Guiné-Bissau dos anos 80 e 90, que, por ter sido mais 
discreta nos anos anteriores nunca deixou de ser importante. Caracterizada também por uma crise social ascendente e sustentada pelo esvaziamento progressivo do conteúdo do Estadoprovidência pela incapacidade crescente das autoridades de fazer frente as suas responsabilidades sociais.

Os efeitos sociais do programa de ajustamento estrutural a partir de 1987, somado ao forte crescimento demográfico registrado nos anos 70 e 80 e o êxodo rural acelerado pela liberalização econômica, criou um quadro crítico feito da fragilização das camadas sociais mais necessitadas, tendo impacto nos índices crescentes de analfabetismo entre as pessoas jovens e adultas na Guiné-Bissau.

\section{Pesquisa Bibliográfica Realizada}

Foram localizadas três dissertações de mestrado e uma tese de doutorado sobre as políticas de Alfabetização de Pessoas Jovens e Adultas na Guiné Bissau, sendo relacionadas a diversidade cultural.

A Dissertação de mestrado de Heldomiro Henrique Correia defendida no Programação de Pós-Graduação da Universidade Federal da Paraíba intitulada "O Projeto Africanidade no Contexto Educacional na Guiné-Bissau”, estudou a evolução do sistema educacional na Guiné-Bissau, entre os anos de 1974 e 2012, considerando suas condições históricas, socioeconômicas e políticas, bem como seus reflexos no desenvolvimento do país e o impacto do projeto africanidade nesse contexto.

A Tese de Doutorado do Lourenço Ocuni CA defendida no Programa de PósGraduação em Educação da Universidade Estadual de Campinas intitulada "Perspectiva Histórica da Organização do Sistema Educacional da Guiné-Bissau", analisou as estruturas educacionais, a falta de infraestrutura deixada pelo colonialismo português e a implementação do novo sistema educacional pelo PAIGC.

A Dissertação de Mestrado de Isabel Quinhones Levy Araújo Ribeiro, defendida no Programa de Pós Graduação em Educação da Universidade Aberta de Lisboa /Portugal, cujo foco consistiu na descrição da vida no bairro de Quelele, as suas gentes, atividades, as políticas de desenvolvimento comunitário levado a cabo pela organização não governamental que atua localmente há cerca de 10 anos, seu título -"Dinâmica do ensino popular na Guiné-Bissau - o caso das escolas populares do bairro de Quelele: uma alternativa para o futuro do sistema educativo".

A Dissertação de Mestrado de Lamine Soncó defendida junto a Universidade do Porto em Portugal intitulada "Alfabetização de jovens e adultos não escolarizados: Uma 
reflexão sobre o contexto guineense", sendo sua centralidade o reconhecimento na prática de projetos na área da alfabetização de jovens e adultos, junto de instituições ou associações em Portugal, de forma a compreender as metodologias e as técnicas que os formadores utilizam para a mobilização de jovens e adultos migrantes no campo educativo.

Todos os trabalhos destacam as línguas locais e revelam a prioridade na alfabetização ocorrer na Língua Portuguesa, sua variação comunicativa no crioulo como construção de resistência dos grupos locais à colonização.

Consideram a diversidade cultural e linguística como riqueza, sendo inerente ao processo de alfabetização de jovens e adultos considerar a necessidade de criação de materiais e conteúdos diferenciados tendo em conta as diversidades culturais e linguísticas. A maioria das sociedades africanas foi estruturada em torno da cultura oral, como sustenta (Faundez, 1989), numa cultura essencialmente de expressão oral, não convém, pois, privilegiar a expressão cultural escrita em detrimento da expressão oral também nos processos de Alfabetização de Pessoas Jovens e Adultas. É indispensável comparar e permitir o desenvolvimento mútuo das duas expressões, uma vez que as formas de linguagem se relacionam com o poder.

\section{Conclusão}

A produção científica sobre Alfabetização de Pessoas Jovens e Adultas e Diversidade Cultural na Guiné Bissau ainda é incipiente, há poucos trabalhos inseridos neste tema.

Com base na revisão de obras de vários autores citados no trabalho, o estudo conclui que o estado guineense precisa implementar no Sistema Educacional políticas para a alfabetização de pessoas jovens e adultos, enquanto políticas públicas destinadas a todo o seu território, contando com a participação da sociedade e valorizando sua variedade linguística e religiosa, para promover o desenvolvimento social do país.

As considerações do filósofo argentino Rodolfo Kusch revelam a importância de conhecermos a "África Profunda" e aí a Alfabetização das Pessoas Jovens e Adultas considerando as línguas locais, a oralidade como um caminho metodológico antes da aprendizagem da escrita e da leitura.

Face a esse contexto, o desafio na promoção da Alfabetização das Pessoas Jovens e Adultas, ocorre na compreensão dos condicionantes de ordem objetiva dentro do contexto do capitalismo atual, como uma necessidade de toda pessoa para sua mínima inclusão na 
sociedade, mas também as implicações de natureza sociocultural, em especial a diversidade linguística e religiosa as quais interferem nos processos de Alfabetização de Pessoas Jovens e Adultas e podem vincular-se aos currículos de seus programas, constituir-se como valorização do modo de ser e das cosmologias das pessoas jovens e adultas da Guiné Bissau.

Neste sentido, a Educação de Pessoas Jovens e Adultas precisa compor um sistema educativo no qual o estudante e o meio social precisam estar absolutamente articulados e isto necessita estar sob a responsabilidade do Estado guineense.

\section{Referências}

BARRETO, Augusto Gomes. O Fraco Desempenho dos Estudantes no Ensino Superior na Guiné-Bissau: A Herança do Ensino Básico. São Paulo, Revista Eletrônica Diálogos Acadêmicos v. $\quad 07, \quad \mathrm{n}^{\mathrm{o}} \quad 2$ 2, p. 18-28, JUL-DEZ, 2014. Disponível em: http://www.semar.edu.br/revista/downloads/edicao7/artigo2_OfracoDesempenhodosEstudant esnoE nsinoSuperior.pdf. Acesso em: 25 de novembro de 2016.

BECKER, Howard S. Métodos de Pesquisa em Ciências Sociais. São Paulo: Hucitec, 1999,

CÁ, Lourenço Ocuni. Estado: políticas públicas e gestão educacional. Cuiabá: EdUFMT, 2010.

Perspectiva Histórica da Organização do Sistema Educacional da Guiné-Bissau. Tese de doutorado. Programa de Pós-Graduação em Educação Universidade Estadual de Campinas, 2005.

CABRAL, Amílcar. Recenseamento agrícola da Guiné: estimativa em 1953. Boletim Cultural da Guiné Portuguesa, 1956.

CORREIA, Heldomiro Henrique. O Projeto Africanidade no Contexto Educacional na Guiné-Bissau. Dissertação de Mestrado. Programa de Pós-Graduação em Educação da Universidade Federal da Paraíba, 2013.

FAUNDEZ, Antônio. Oralidade e escrita: experiências educacionais na África e na América Latina. Rio de Janeiro: Paz e Terra, 1989.

FREIRE, Paulo. Política e educação: ensaios. São Paulo: Cortez, 2001.

FREIRE, Paulo. Pedagogia da autonomia: saberes necessários à prática docente. São Paulo: Paz e Terra, 2003.

GOMES, Arrais Fidelis da Silva. Políticas Educacionais de Alfabetização de Jovens e Adultos na Guiné-Bissau: A Presença do Método Alpha TV. Dissertação de mestrado. Programa de Pós-Graduação em Educação da Universidade Federal do Rio Grande do Sul, 2018.

GUINÉ-BISSAU. Instituto Nacional de Estatística. Censo Demográfico 2009. 
KUSCH, Rodolfo, América Profunda Buenos Aires, Biblos, 1999.

MACEDO, Donaldo, Alfabetização, linguagem e ideologia. Revista Educação \& Sociedade. Campinas (SP), ano XXI, no. 73, dezembro de 2000, p. 84-99.

RIBEIRO, Isabel Quinhones Levy Araújo. Dinâmica do ensino popular na Guiné-Bissau - o caso das escolas populares do bairro de Quelele: uma alternativa para o futuro do sistema educativo. Dissertação de Mestrado em Comunicação Educacional Multimédia. Universidade Aberta de Lisboa, 2001.

SAMBÚ, Queba. Ordem para matar: dos fuzilamentos ao caso das bombas da embaixada de Guiné. Lisboa, Edições Referendo:1989.

SILVA, Fernando Delfim Da. Guiné-Bissau: páginas de história política, rumos da democracia. Bissau, Firquidja editora: 2003.

SONCÓ, Lamine. Alfabetização de jovens e adultos não escolarizados: Uma reflexão sobre o contexto guineense. Dissertação de Mestrado: Universidade do Porto, 2014. 